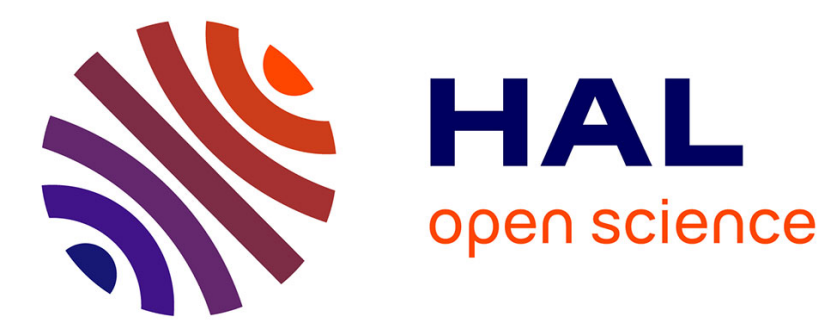

\title{
3D kinematic and dynamic analysis of the front crawl tumble turn in elite male swimmers
}

Frédéric Puel, J. Morlier, Marta Avalos, M. Mesnard, M. Cid, Philippe Hellard

\section{To cite this version:}

Frédéric Puel, J. Morlier, Marta Avalos, M. Mesnard, M. Cid, et al.. 3D kinematic and dynamic analysis of the front crawl tumble turn in elite male swimmers. Journal of Biomechanics, 2012, 45 (3), pp.510-515. 10.1016/j.jbiomech.2011.11.043 . hal-01727368

\section{HAL Id: hal-01727368 https://hal-insep.archives-ouvertes.fr/hal-01727368}

Submitted on 9 Mar 2018

HAL is a multi-disciplinary open access archive for the deposit and dissemination of scientific research documents, whether they are published or not. The documents may come from teaching and research institutions in France or abroad, or from public or private research centers.
L'archive ouverte pluridisciplinaire HAL, est destinée au dépôt et à la diffusion de documents scientifiques de niveau recherche, publiés ou non, émanant des établissements d'enseignement et de recherche français ou étrangers, des laboratoires publics ou privés. 


\title{
3D kinematic and dynamic analysis of the front crawl tumble turn in elite male swimmers
}

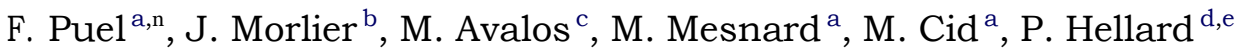 \\ ${ }^{a}$ Univ. Bordeaux, I2M, UMR CNRS 5295 Talence, France \\ ${ }^{\mathrm{b}}$ Univ. Bordeaux, INCIA, UMR CNRS 5287 Bordeaux, France \\ ${ }^{c}$ Epidemiology and Biostatistics Research Centre, INSERM U897 Bordeaux, France \\ ${ }^{\mathrm{d}}$ Fédération Franeaise de Natation, Pantin, France \\ ${ }^{\mathrm{e}}$ Institut de Recherche bioMédicale et d'F́idémiologie du Sport (IRMES), Paris, France
}

\section{a r t i 1 e i n fo}

\section{Article history:}

Accepted 18 November 2011

\section{Keywords:}

Kinematics

Dynamics

Lasso method

Swimming

Turn

\begin{abstract}
a b s t r a c t
The aim of this study was to identify kinematic and dynamic variables related to the best tumble turn times (3mRTT, the turn time from 3-m in to 3-m out, independent variable) in ten elite male swimmers using a three-dimensional (3D) underwater analysis protocol and the Lasso (least absolute shrinkage and selection operator) as statistical method. For each swimmer, the best-time turn was analyzed with five stationary and synchronized underwater cameras. The 3D reconstruction was performed using the Direct Linear Transformation algorithm. An underwater piezoelectric 3D force platform completed the set-up to compute dynamic variables. Data were smoothed by the Savitzky-Golay filtering method. Three variables were considered relevant in the best Lasso model (3mRTT 1/42.58 - 0.425 RD p 0.204 VPe p $0.0046 \mathrm{TD})$ : the head-wall distance where rotation starts (RD), the horizontal speed at the force peak (VPe), and the 3D length of the path covered during the turn (TD). Furthermore, bivariate analysis showed that upper body (CUBei) and lower limb extension indexes at first contact (CLLei) were also linked to the turn time ( $r 1 / 4-0.65$ and $p 00.05$ for both variables). Thus the best turn times were associated with a long $\mathrm{RD}$, slower $\mathrm{VPe}$ and reduced TD. By an early transverse rotation, male elite swimmers reach the wall with a slightly flexed posture that results in fast extension. These swimmers opt for a movement that is oriented forward and they focus on reducing the distance covered.
\end{abstract}

\section{Introduction}

Nowadays, all competitive freestyle swimmers use the tumble turn technique. Olympic race analyses and research studies have highlighted the performance in an event, which is related to the turn times (men's 100-m and 200-m freestyle times and both turn-in and turn-out times, rZ0.91, po0.05, Arellano et al., 1994; 50-m time and 5-m round-trip time, $r^{1} / 40.90, p 00.05$, Blanksby et al., 1996; 50-m time and 2.5-m round-trip time, $r^{1 / 4}$ 0.85, po0.05, Cossor et al., 1999). The Australian Institute of Sport analyzed the men's 200-m freestyle final during the 2000 Sydney Olympics Games and provided a good example of the importance of turns for the final race outcome: although slower than the fourth swimmer during the swum phases, the bronze medalist reached the podium because of better turn times.

Many authors have used correlations and multiple linear regression to determine whether changes in turn times depend on a combination of dynamic and kinematic variables. By stepwise

${ }^{\mathrm{n}}$ Correspondence to: I2M, UMR CNRS 5295 (ex-LMP), 351 cours de la Libération, 33405 Talence cedex, France. Tel.: p33 681382 708; fax: p33 540006964.

E-mail address: fred_puel@hotmail.com (F. Puel). regression in 36 young swimmers, Blanksby et al. (1996) found that the best predictors for a good $5 \mathrm{mRTT}$ (the turn time from $5-\mathrm{m}$ in to 5-m out) were high peak force (exerted perpendicular to the wall), a swim resumption performed far from the wall, long head-wall distance when swimmers begin their transverse rotation, and tallness. These variables accounted for $55 \%$ of the variance. In a nearly identical population, Cossor et al. (1999) found similar results, with negative correlations between the $2.5 \mathrm{mRTT}$ (the turn time from $2.5-\mathrm{m}$ in to 2.5-m out) and the peak force, the peak of normalized force, the tuck index (i.e., the ratio between the distance from the wall to the greater trochanter and the swimmer's trochanteric height), and the average speed over $0.6 \mathrm{~m}$ after the push-off. In 38 adult swimmers, Pereira et al. (2006) observed that the variable of peak normalized force contributed most to turn performance during front crawl swimming.

Differences in distances concerning the beginning and completion of tumble turns make direct comparisons between studies difficult (Vilas-Boas and Fernandes, 2003). Blanksby et al. (1996) and Cossor et al. (1999) used short distances (2.5mRTT), ending the turn before completion of the gliding phase $(2.62 \mathrm{~m}$ in elite female swimmers, Puel et al., 2011). Other studies and race analyses have used longer distances, including much more swim cycles at approach and after swimming resumption (Silveira, 2007), which reduce the influence 
of turning technique on the recorded times: $3-\mathrm{m}$ in to $6.5-\mathrm{m}$ out (Thayer and Hay, 1984), 5mRTT (Blanksby et al., 1996; Lyttle et al., 1999), or 7.5mRTT (Arellano et al., 1994; Lyttle and Mason, 1997; Pereira et al., 2006). Therefore, the 3mRTT (Nicol and Kruger, 1979) was chosen to study elite swimmers' turns.

The challenge of designing accurate and reliable equipment for underwater analysis (Hay, 1988; Vilas-Boas and Fernandes, 2003) and the lack of three-dimensional (3D) turn studies have impeded the analysis of the forces and impulses in the vertical plane of the wall and the lateral moves of the swimmer; it has thus been difficult to accurately identify the first contact (Lyttle and Mason, 1997), determine the push-off angles, and estimate the length of the path covered. The present study relied on an extensive protocol for 3D underwater analysis to assess a large set of kinematic and dynamic performance variables. It was assumed that an inter-swimmer analysis with 10 elite swimmers would help to identify the kinematic and dynamic variables related to the best turn times using multivariate and conventional univariate statistical methods.

\section{Methods}

\subsection{Subjects and procedure}

Ten elite male swimmers participated in this study (Table 1) after giving informed consent to the experimentation. The participants were asked to perform crawl tumble turns as fast as possible. They regularly practice this kind of turn and use it for competition races. The coaches timed each turn and the experimenters ensured that both the swimmer's feet hit the force platform mounted on the turning wall. For each swimmer, only the turn with the best time was analyzed.

\subsection{Experimental set-up}

The swimmers were analyzed when passing through a parallelepiped calibrated space (Wood and Marshall, 1986; Challis and Kerwin, 1992; Chen et al., 1994) with mean dimensions of $4.82 \mathrm{~m} \times 1.11 \mathrm{~m} \times 1.85 \mathrm{~m}$ for the horizontal (main movement direction), vertical (pool depth) and lateral (lane width) directions, placed in contact with the turning wall and the water surface. Five stationary mini-DV video cameras (Sony DCR-HC62E and DCR-HC96E, 50 frames per second, shutter speed: $1 / 120 \mathrm{~s}$ ) were located underwater at different depths in waterproof cases (Sony SPK-HCD) on a semi-ellipse centered on the turn place (Fig. 1). Their synchronization was obtained using an underwater strobe flash.

A piezoelectric 3D force platform (Kistler 9253B12, $2000 \mathrm{~Hz}$ ) was also mounted underwater on the turning wall. Dynamic data capture was carried out by an 8-channel charge amplifier and a DAQ system with BioWare software (Kistler 9865E1Y28 and 5691A1).

Kinematic and dynamic data were synchronized at the end of the push-off.

\subsection{Measurements}

One complete turn was analyzed for each swimmer by manual digitizing of the head, which is visible during most of the movement. Sixteen other anatomical points were also digitized (left and right big toes, ankles, knees, hips, shoulders, elbows, wrists, and fingertips). Their 3D coordinates were used to define a sevensegment model of the swimmer during the rotation and contact phases (feet, legs, thighs, trunk, head, arms, and forearms-hands; Winter, 1990; Sanders, 2002; Vilas-Boas and Fernandes, 2003). It was used to assess the body extension indexes.

2D image coordinates were transformed to 3D object-space coordinates using the Direct Linear Transformation algorithm (Abdel-Aziz and Karara, 1971; Elipot et al., 2009). The mean 3D distance between the real coordinates of the 14

Table 1

Characteristics of the ten male swimmers.

\begin{tabular}{lrllll}
\hline & $\begin{array}{l}\text { Age, } A \\
\text { (years) }\end{array}$ & $\begin{array}{l}\text { Body mass, } \\
\text { BM (kg) }\end{array}$ & $\begin{array}{l}\text { Height, BH } \\
(\mathrm{m})\end{array}$ & $\begin{array}{l}\text { Performance, } \\
L(\%)\end{array}$ & $\begin{array}{l}\text { Turn time, } \\
\text { 3mRTT }(\mathrm{s})\end{array}$ \\
\hline Mean & 19.7 & 80.3 & 1.87 & 91 & 2.62 \\
S.D. & 3.5 & 9.7 & 0.09 & 4 & 0.12 \\
Min & 14.9 & 68 & 1.73 & 85.1 & 2.41 \\
Max & 24.9 & 96 & 2.02 & 96.6 & 2.78
\end{tabular}

Performance level, $L(\%)$ is the ratio between the $200 \mathrm{~m}$ freestyle world record and the swimmer's best performance. S.D. means standard deviation.

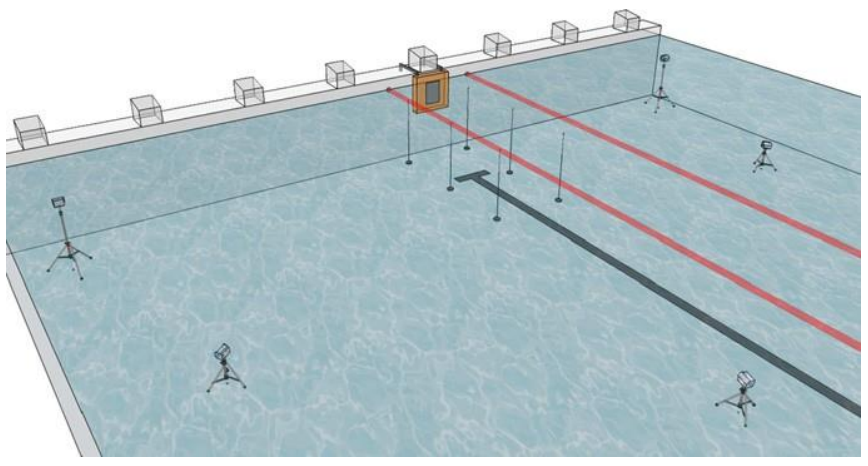

Fig. 1. 3D kinematic calibration system and camera set-up. The two cameras that were close to the turning wall were about $0.7-\mathrm{m}$ deep. The two following cameras (from the turning wall to the other end of the pool) were placed as deep as possible (pool depth). The fifth camera was placed in a center lane of the pool and was about $1.5-\mathrm{m}$ deep. The angle between each pair of consecutive cameras ranged from 451 to 601

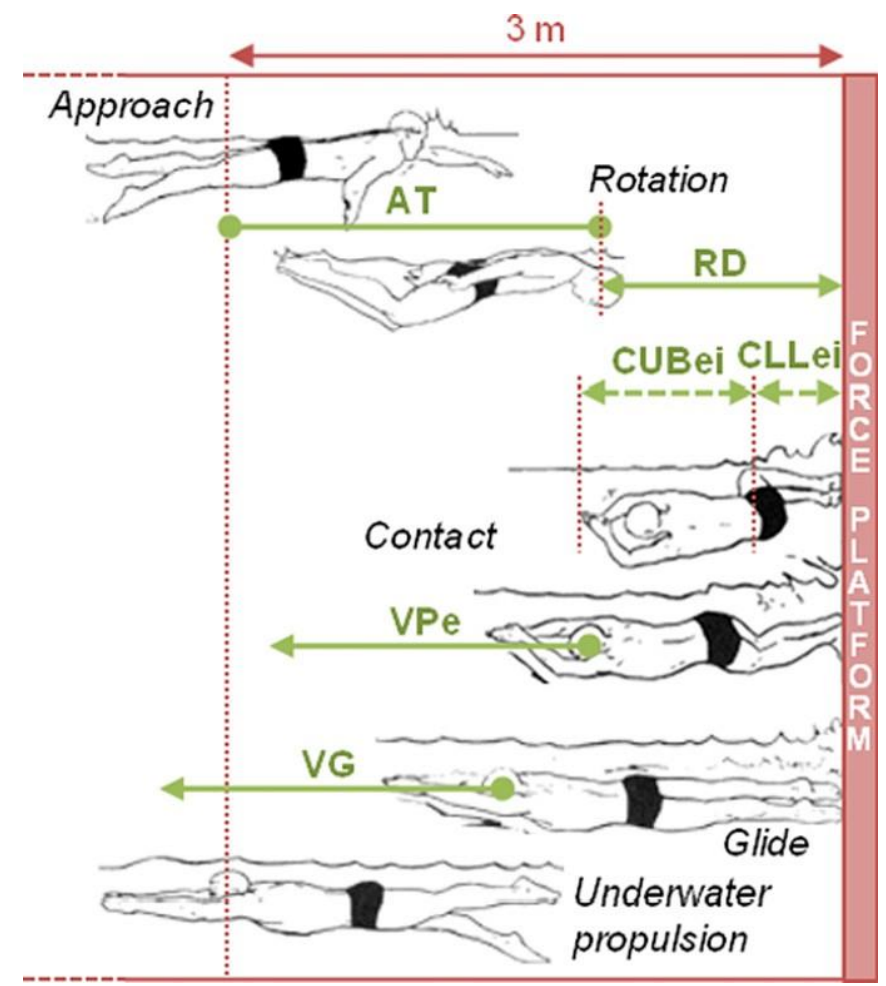

Fig. 2. Selected variables. AT is the time of approach (in s), RD is the head-to-wall distance at rotation (in $\mathrm{m}$ ), CLLei is the lower limb extension index at first contact, CUBei is the upper limb extension index at first contact, VPe is the horizontal speed of the swimmer's head at force peak (in $\mathrm{m} / \mathrm{s}$ ), and VG is the horizontal speed at the end of push-off, i.e., the beginning of the glide (in $\mathrm{m} / \mathrm{s}$ ).

calibration points and the calculated coordinates was $0.01670 .011 \mathrm{~m}(0.043 \mathrm{~m}$ for maximal distance), which was satisfactory in light of the calibrated space (Psycharakis et al., 2005).

Kinematic and dynamic data were smoothed by the Savitzky-Golay filtering method (degree of polynomials: $d 1 / 42$; moving window sizes: $w_{\mathrm{k}} 1 / 413, w_{\mathrm{d}} 1 / 465$; Savitzky and Golay, 1964), recently used to study underwater (Domenici et al., 2000) and human movements (Sibella et al., 2007).

Eleven temporal (absolute and relative times), thirty kinematic (horizonta speeds and distances, depths, body extension indexes) and ten dynamic variables (forces, impulses and decompositions of the force vector at the horizontal force peak) were computed for each turn (Table 3 and Fig. 2). For example, time factors were $3 \mathrm{mRTT}$, the time interval when the horizontal position of the swimmer's head is below $3 \mathrm{~m}$, or AT, the approach duration; velocity factors were VPe, the horizontal speed of the swimmer's head at the force peak, or VG, at the end of push-off; distances were RD, the head-wall distance when the swimmer began his transverse rotation, or $\mathrm{TD}$, the $3 \mathrm{D}$ length of the path covered during the turn Lower limb extension indexes were the ratios between the hips-wall distance at 
chosen key times: first contact, end of placement (Lyttle et al., 1999; Prins and Patz, 2006), force peak, and end of push-off (respectively, CLLei, PoLLei, PeLLei, and GLLei) and the sum of foot, leg, and thigh lengths. Similarly, upper body extension indexes (CUBei, PoUBei, PeUBei, and GUBei) were the ratios between the fingerships distance and the sum of trunk, arm, forearm, and hand lengths.

\subsection{Statistics}

To determine whether changes in turn performance (3mRTT as response) depend on a combination of variables, an innovative multivariate analysis was conducted.

Conventional multivariate methods are not well adapted to problems where the number of explanatory variables exceeds the number of observations. Penalization methods, such as the Lasso, have thus emerged and become popular alternatives.

The Lasso is a penalization and variable selection method initially proposed for linear regression (Tibshirani, 1996). The vector of parameters is estimated by minimizing the least squares criterion with a constraint on the sum of the absolute coefficient values or, equivalently, by minimizing the quadratic criterion penalized by the $\mathrm{L}_{1}$-norm of the coefficients. The introduction of a penalization reduces the variability of the estimate, thereby improving the accuracy of prediction. Furthermore, $\mathrm{L}_{1}$-type penalization shrinks some of the coefficients, while the others are canceled exactly, leading to more parsimonious models. This penalization can therefore automatically eliminate the irrelevant variables.

We used the leave-one-out cross-validation to estimate the proper amount of shrinkage. To measure the model stability, confidence intervals at $95 \%$ were calculated by nonparametric bootstrap (Nakagawa and Cuthill, 2007). The Lasso regression was performed with 2000 bootstrap replications, by resampling from the observed data.

Classical bivariate analyses (Pearson's correlations) were also conducted to determine the relationships between explanatory variables and the turn time and then the relationships between each pair of variables.

\section{Results}

Three variables were relevant in the best Lasso model (Eq. (1)): the place where rotation starts (RD), the horizontal speed at the force peak (VPe, Fig. 5), and the 3D length of the path covered during the turn (TD, Fig. 4).

\section{3mRTT 1/4 2:58-0:425 RDp 0:204 VPe p 0:0046TD}

Confidence intervals at $95 \%$ of the estimated coefficients are shown in Table 2. Before analysis, 11 duration variables were excluded because they were redundant with the independent variable $3 \mathrm{mRTT}$ and probably correlated.

In addition, Pearson's correlations showed that RD $\left(r^{1 / 4}-0.88\right.$, po 0.01, Fig. 3), VPe ( $r^{1 / 40.82, ~ p o ~ 0.01, ~ F i g . ~ 3), ~ A T ~(a p p r o a c h ~}$ duration, $r^{1 / 40.79}$, po 0.01), TD ( $r^{1 / 40.68}$, po 0.05), CUBei, and CLLei (extension indexes at first contact, $r^{1 / 4}-0.65$ and $p 00.05$ for both variables) were linked to the turn time (Table 2).

\section{Discussion}

The best tumble turn times in this study were characterized by a long head-wall distance where rotation starts (RD), slower horizontal speed at the force peak (VPe), and reduced length of the path covered during the turn (TD, Fig. 4).

The place where rotation starts is the horizontal distance from the swimmer's head to the wall when the head begins to sink underwater. The results indicated that the swimmers with the fastest turns initiated their rotation farther from the wall (Table 2 and Fig. 3). In younger swimmers, Blanksby et al. (1996) observed similar results: the place where rotation starts was one of the best indicators of turn performance and the best swimmers initiated their turns farther from the wall than the slower ones. The distances reported by Blanksby $(0.6270 .18 \mathrm{~m})$ were shorter than those found for taller swimmers like the experts in the current study $(1.270 .13 \mathrm{~m})$ or Lyttle and Mason's crawlers $(0.9770 .05 \mathrm{~m}$; 1997). This suggests that swimmers' stature could play a role in the head-wall distance at rotation, which was another result of Blanksby. In the current study, the high correlation coefficient between the distance and stature $\mathrm{RD}$ and $\mathrm{BH}$, $\left.r^{1} / 40.82, p 00.01\right)$ reinforced this assumption. In addition, as it could be expected but never reported previously, the approach duration (AT, time to swim between $3 \mathrm{~m}$ and the rotation) was both positively correlated with the turn time (Table 2) and negatively correlated with the rotation distance $\left(r^{1 / 4}-0.92, p 00.01\right)$.

The velocity factor VPe is the horizontal speed of the swimmer's head when the horizontal force component recorded by the force platform is at its highest point (Fig. 5). The results indicated that the best turns were characterized by reduced speed at the force peak (Table 2 and Fig. 3). Although no previous study computed the velocity at the force peak, this result is surprising but can be explained in light of Lyttle's assumption (Lyttle et al., 1999). Computing the velocity of 30 experienced male swimmers along the push-off, these authors analyzed the relationships between dynamic and hydrodynamic parameters and the velocity at the end of the pushoff. They found a positive correlation between the push-off phase duration and the speed at the end of the push-off $\left(r^{1 / 4} 40.42, p 00.05\right)$. These authors suggested that longer wall push-off times could lead to faster velocities but advised readers that too much time spent on the wall could be directly prejudicial to performers by an increase of the turn time and a decrease of the overall performance. The results of the present study showed a similar tendency: the longer the time to reach the force peak (PeT), the higher the speed at the peak was $(r 1 / 40.58, p 00.1)$. This positive trend was maintained, given the total push-off time (PoT, $r^{1 / 4}$ 0.52) and also the total wall contact time (CT, $r^{1 / 4}$ 0.41). The correlation coefficients of these three durations with the turn time (3mRTT, $r^{1 / 4} 0.55,0.52$, and 0.48 ) suggested that the low turn times of these elite swimmers were linked to reduced contact and push-off durations, i.e., fast extension.

Another explanation for reduced speed at the force peak is found in the negative correlation between the lower limb extension index at first contact (CLLei) and the turn time (Table 2): the more extended the lower limbs (in the range of measured values), the better the turn time was. Similar results were reported by

Variables which most influence the turn time (3mRTT).

\begin{tabular}{|c|c|c|c|c|c|c|c|}
\hline & & $\mathrm{RD}(\mathrm{m})$ & $\operatorname{VPe}(\mathrm{m} / \mathrm{s})$ & $\mathrm{AT}(\mathrm{s})$ & $\mathrm{TD}(\mathrm{m})$ & CUBei & CLLei \\
\hline & Mean & 1.2 & 2.59 & 0.99 & 4.88 & 0.82 & 0.57 \\
\hline & S.D. & 0.13 & 0.14 & 0.09 & 0.31 & 0.09 & 0.07 \\
\hline & Min & 1.07 & 2.33 & 0.81 & 4.32 & 0.72 & 0.44 \\
\hline & $\operatorname{Max}$ & 1.43 & 2.82 & 1.11 & 5.32 & 0.95 & 0.64 \\
\hline \multirow[t]{2}{*}{ Lasso } & Coef. & -0.425 & 0.204 & - & 0.0046 & 0 & 0 \\
\hline & $95 \% \mathrm{CI}$ & {$[-0.905,0]$} & {$[0,0.459]$} & - & {$[0,0.186]$} & {$[0,0]$} & {$[-0.482,0]$} \\
\hline \multirow[t]{2}{*}{ Pearson } & $r$ & -0.88 & 0.82 & 0.79 & 0.68 & -0.65 & -0.65 \\
\hline & $p$ & 00.01 & 00.01 & 00.01 & 00.05 & 00.05 & 00.05 \\
\hline
\end{tabular}

CI means confidence interval. An upper or lower confidence limit of 0 indicates that the variable was eliminated from at least $2.5 \%$ of the bootstrap samples. Results are ranked by increasing Pearson's $p$-value. 
Table 3

Means 7S.D. (standard deviation), Pearson's correlations with the turn time (3mRTT), and definitions of the 51 variables analyzed.

\begin{tabular}{|c|c|c|c|c|}
\hline Variable (unit) & Mean7S.D. & r & $\mathrm{p}$ & Definition \\
\hline $3 \mathrm{mRTT}(\mathrm{s})$ & 2.6270 .12 & - & - & $\begin{array}{l}3 \mathrm{mRTT} \text { is for the } 3 \mathrm{~m} \text { round trip time and is the turn time from } 3 \mathrm{~m} \text { in to } 3 \mathrm{~m} \\
\text { out }\end{array}$ \\
\hline AT (s) & 0.9970 .09 & 0.79 & 0.007 & Approach time \\
\hline $\mathrm{RT}(\mathrm{s})$ & 0.8570 .07 & -0.18 & 0.62 & Rotation time \\
\hline $\mathrm{CT}(\mathrm{s})$ & 0.3470 .05 & 0.48 & 0.16 & Contact time \\
\hline $\mathrm{BT}(\mathrm{s})$ & 0.1170 .01 & -0.32 & 0.36 & $\begin{array}{l}\text { BT is the placement time. The letter "B" refers to the notion of "braking" for an } \\
\text { analogy with gait analysis }\end{array}$ \\
\hline BP $(\%)$ & 33.477 .1 & -0.48 & 0.16 & $\mathrm{BT} / \mathrm{CT}$ ratio \\
\hline $\operatorname{PoT}(\mathrm{s})$ & 0.2370 .05 & 0.52 & 0.13 & Push-off time one can note that BTpPoT $1 / 4 \mathrm{CT}$ \\
\hline $\operatorname{PeT}(\mathrm{s})$ & 0.1470 .05 & 0.55 & 0.10 & $\mathrm{PeT}$ is the time to reach the force peak (from the push-off beginning). \\
\hline $\mathrm{PeP}(\%)$ & 60.278 .9 & 0.49 & 0.15 & $\mathrm{PeT} / \mathrm{PoT}$ ratio \\
\hline GT (s) & 0.3270 .14 & -0.05 & 0.90 & Glide time \\
\hline UT (s) & 1.2370 .47 & 0.08 & 0.83 & Underwater propulsion time \\
\hline $\operatorname{VIn}(\mathrm{m} / \mathrm{s})$ & -1.7770 .16 & 0.11 & 0.73 & $\begin{array}{l}\text { Horizontal speed of the swimmer's head at the beginning of the turn }(3 \mathrm{~m} \\
\text { before the wall). Negative values are due to the kinematic base used }\end{array}$ \\
\hline $\mathrm{V} 1 \mathrm{mR}(\mathrm{m} / \mathrm{s})$ & -1.7870 .07 & 0.02 & 0.97 & Speed $1 \mathrm{~m}$ before the rotation \\
\hline $\operatorname{VR}(\mathrm{m} / \mathrm{s})$ & -1.9070 .18 & 0.30 & 0.40 & Speed at rotation \\
\hline $\mathrm{VC}(\mathrm{m} / \mathrm{s})$ & 0.4070 .29 & -0.66 & 0.04 & Speed at first contact \\
\hline $\operatorname{VPo}(\mathrm{m} / \mathrm{s})$ & 1.2570 .49 & -0.46 & 0.18 & Speed at the push-off beginning \\
\hline $\operatorname{VPe}(\mathrm{m} / \mathrm{s})$ & 2.5970 .14 & 0.82 & 0.004 & Speed at the force peak \\
\hline $\operatorname{Vmax}(\mathrm{m} / \mathrm{s})$ & 2.7970 .12 & 0.35 & 0.32 & Maximal speed \\
\hline VG $(\mathrm{m} / \mathrm{s})$ & 2.7870 .13 & 0.26 & 0.47 & Speed at the end of push-off \\
\hline DVPo $(\mathrm{m} / \mathrm{s})$ & 1.5370 .54 & 0.48 & 0.16 & Gain of speed along the push-off phase DVPo $1 / 4 \mathrm{VG}-\mathrm{VPo}$ \\
\hline $\mathrm{VU}(\mathrm{m} / \mathrm{s})$ & 2.1770 .19 & 0.13 & 0.72 & Speed at the beginning of underwater propulsion \\
\hline VOut $(\mathrm{m} / \mathrm{s})$ & 2.1770 .20 & -0.22 & 0.55 & Speed at the end of the turn ( $3 \mathrm{~m}$ after the wall) \\
\hline $\operatorname{VS}(\mathrm{m} / \mathrm{s})$ & 1.6470 .21 & -0.20 & 0.57 & Speed at swim resumption \\
\hline $\mathrm{RD}(\mathrm{m})$ & 1.2070 .13 & -0.88 & 0.001 & Head-wall distance at rotation \\
\hline $\mathrm{D} 22(\mathrm{~m})$ & 2.7070 .29 & -0.25 & 0.48 & Head-wall distance when the speed goes down to $2.2 \mathrm{~m} / \mathrm{s}$ \\
\hline $\mathrm{D} 19$ (m) & 3.4370 .45 & -0.38 & 0.27 & Head-wall distance when the speed goes down to $1.9 \mathrm{~m} / \mathrm{s}$ \\
\hline $\mathrm{UD}(\mathrm{m})$ & 2.7170 .36 & -0.22 & 0.54 & Head-wall distance at underwater propulsion beginning \\
\hline $\mathrm{SD}(\mathrm{m})$ & 4.9970 .62 & -0.06 & 0.86 & Head-wall distance at swim resumption \\
\hline $\mathrm{TD}(\mathrm{m})$ & 4.8870 .31 & 0.68 & 0.03 & Total distance covered (from $3 \mathrm{~m}$ in to $3 \mathrm{~m}$ out) \\
\hline $\mathrm{CDe}(\mathrm{m})$ & -0.3170 .09 & -0.03 & 0.92 & Swimmer's depth at first contact \\
\hline PoDe $(\mathrm{m})$ & -0.3270 .08 & -0.11 & 0.75 & Depth at push-off beginning \\
\hline PeDe $(\mathrm{m})$ & -0.3870 .08 & -0.35 & 0.32 & Depth at force peak \\
\hline GDe $(\mathrm{m})$ & -0.4170 .07 & -0.27 & 0.45 & Depth at the end of push-off \\
\hline CLLei & 0.5770 .07 & -0.65 & 0.04 & Lower limb extension index at first contact \\
\hline PoLLei & 0.6270 .08 & -0.60 & 0.06 & Lower limb extension index at beginning of push-off \\
\hline PeLLei & 0.8170 .06 & -0.33 & 0.35 & Lower limb extension index at force peak \\
\hline GLLei & 1.0170 .05 & -0.33 & 0.35 & Lower limb extension index at the end of push-off \\
\hline CUBei & 0.8270 .09 & -0.65 & 0.04 & Upper body extension index at first contact \\
\hline PoUBei & 0.9070 .06 & -0.48 & 0.16 & Upper body extension index at beginning of push-off \\
\hline PeUBei & 0.9670 .04 & -0.14 & 0.69 & Upper body extension index at force peak \\
\hline GUBei & 0.9870 .03 & -0.20 & 0.58 & Upper body extension index at beginning of glide \\
\hline $\operatorname{Pe}(\mathrm{N})$ & 12107268 & -0.61 & 0.06 & $\begin{array}{l}\text { Maximal value of the horizontal component of the force during the push-off } \\
\text { (force peak) }\end{array}$ \\
\hline $\mathrm{nPe}$ & 1.5470 .29 & -0.33 & 0.35 & Force peak normalized by the swimmer's body weight \\
\hline LBI (N s) & 1074 & -0.15 & 0.68 & $\begin{array}{l}\text { Impulse of the lateral component of the force (lateral impulse) during the } \\
\text { placement phase }\end{array}$ \\
\hline LPoI (N s) & 1374 & -0.03 & 0.94 & Lateral impulse during the push-off \\
\hline VPoI (N s) & 30716 & -0.21 & 0.56 & Vertical impulse during the push-off \\
\hline HPoI (N s) & 200761 & -0.11 & 0.77 & Horizontal impulse during the push-off \\
\hline HPeI (N s) & 126745 & 0.14 & 0.71 & Horizontal impulse to the force peak \\
\hline HPeIP $(\%)$ & 62.279 .1 & 0.54 & 0.11 & HPeI/HPoI ratio \\
\hline vA (deg.) & 8.074 .9 & -0.07 & 0.85 & Vertical angle of the force vector at the horizontal peak \\
\hline $1 A^{\text {abs }}$ (deg.) & 3.272 .5 & -0.20 & 0.58 & Absolute value of the lateral angle of the force vector at the peak \\
\hline
\end{tabular}

The abbreviations of the variables follow several rules:

- a "T" for the last letter refers to the notion of time or duration,

- a "V" for the first letter refers to velocity and indicates the horizontal speed of the swimmer's head,

- a " $\mathrm{D}$ " means horizontal head-to-wall distance, except for TD which is the total 3D distance covered during the turn,

- "De" at the end means depth (vertical distance between the head and the surface),

- "ei" at the end means extension index, and

- an "I" for the last letter means impulse.

Additionally:

- "C" means that the variable is determined at first contact and similarly,

- "Po" means at the beginning of push-off,

- "Pe" means at horizontal force peak, and

- "G" means at the end of push-off, i.e., the beginning of the glide.

The last 2 abbreviations used are "UB" and "LL" and refer exclusively to extension indexes:

- "UB" is for upper body and

- "LL" is for lower limbs. 
Cossor et al. (1999) in young swimmers, with a negative correlation between the tuck index and the 2.5mRTT ( $r^{1 / 4}-0.56$, po0.05). In 23 adult swimmers, Prins and Patz (2006) studied the influence of three biomechanical parameters linked to the contact phase on the velocity of the early glide: the ratio between push-off time and whole contact time, the foot plant index (i.e., the ratio between the depth offoot-plant and the swimmer's trochanteric height), and the tuck index, which was the only variable significantly correlated with speed. The negative relationship between the tuck index and speed indicated that the more the swimmers flexed their legs (ankles and knees), the greater the speed was. Regarding this speed, Cossor et al. (1999) also showed a negative correlation between $2.5 \mathrm{mRTT}$ and the average speed during the early glide $\left(r^{1 / 4}-0.52\right.$, po0.05), in agreement with Blanksby et al. (1996), who showed that the best turn times were performed with greater maximal

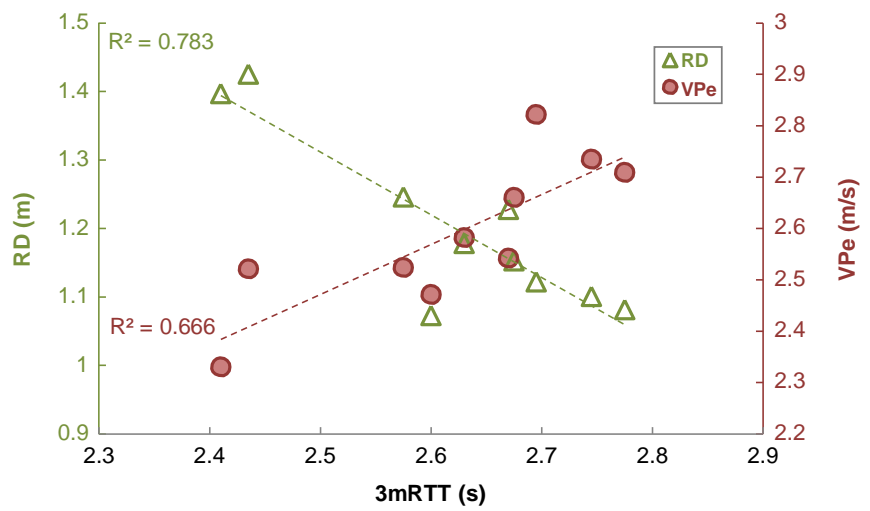

Fig. 3. Horizontal distance between the head of the swimmer and the wall at the beginning of the rotation $(\mathrm{RD}, \mathrm{m})$ and horizontal speed of the head at the force peak $(\mathrm{VPe}, \mathrm{m} / \mathrm{s})$ versus turn time $(3 \mathrm{mRTT}, \mathrm{s})$. speed. By combining our results with these of Prins, Cossor and Blanksby, it seems that two strategies can decrease the turn time. The first, used by less experienced swimmers, is to increase the push-off speed with more flexed legs at contact. The second, adopted by the presented male swimmers, is to shorten the extension phase by less flexed legs at contact.

The observation that less skilled swimmers and expert swimmers use slightly different strategies could explain the finding that the horizontal force peak was not identified as a key biomechanical variable of the turn in the present study, whereas this was the case for theyounger swimmers (Blanksbyetal., 1996; Cossoretal., 1999). Nevertheless, our results also showed a negative though not significant correlation $\left(r^{1 / 4}-0.61, p^{1 / 40} 0.06\right)$, but this trend disappeared

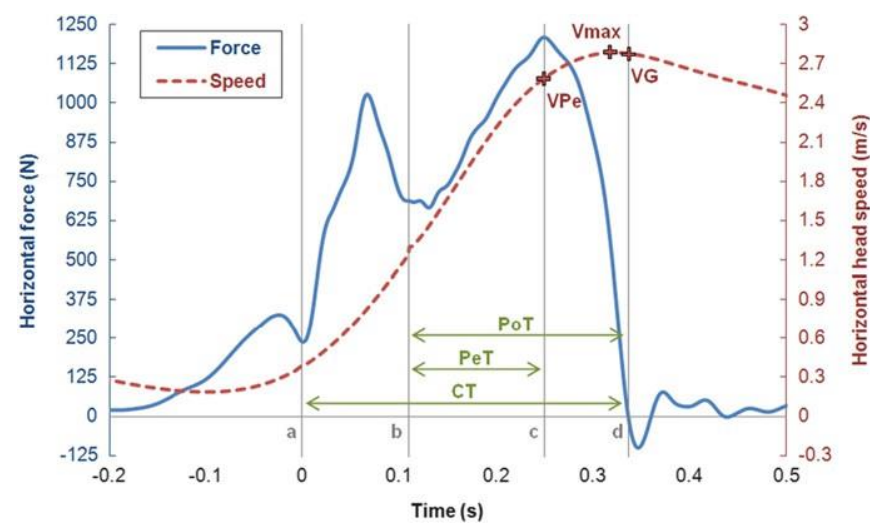

Fig. 5. Mean horizontal component of the force applied on the turning wall and mean horizontal speed of the head for the ten elite swimmers. Vertical gray lines point out the first contact (a), the end of placement (b), the force peak (c), and the end of push-off (d). CT, PeT and PoT are durations between these key times. VPe, Vmax and VG are selected horizontal speeds.
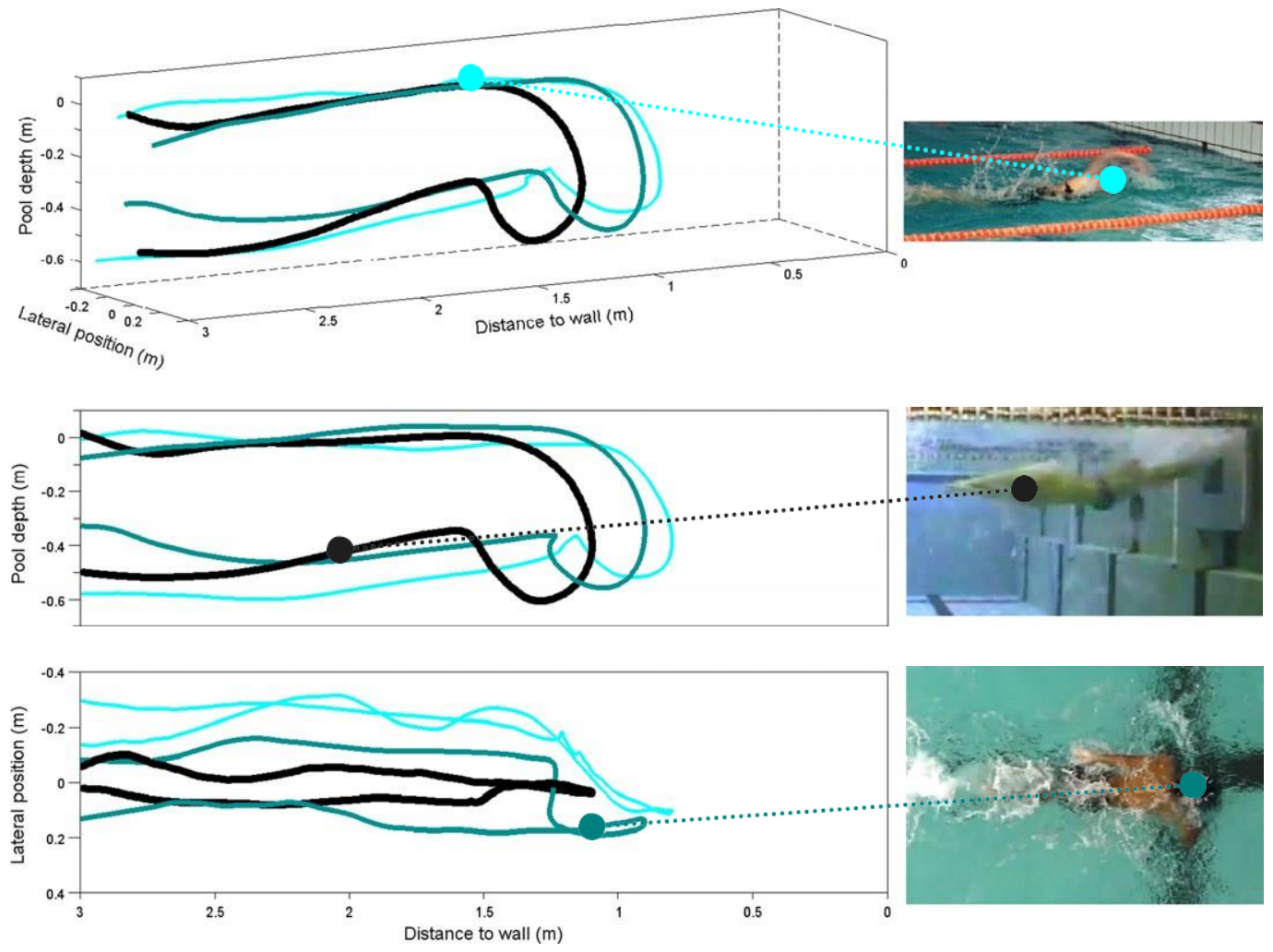

Fig. 4. Head trajectories (TD, $\mathrm{m}$ ) of three selected swimmers. Thicker and darker lines mean shorter turn times and trajectories. Upper view is in 3D mode, middle view is from the side and bottom view is from the air. The three pictures do not represent participants of this study. 
when the value of the force peak was normalized by the swimmer's weight $\left(r^{1} 1 / 4-0.33\right)$, whereas the correlation was maintained for Cossor $\left(r^{1 / 4}-0.66\right)$. It could be speculated that the impulse is a more interesting parameter than just the value of the force peak. On this point, Lyttle et al. (1999) recalled that all previous studies (Nicol and Kruger, 1979; Blanksby et al., 1996; Lyttle and Mason, 1997) had presented the horizontal impulse of the whole contact time and not just the push-off time, which substantially increased its value and prevented the comparison of results. Indeed, the horizontal impulse recorded before the push-off (i.e., during the placement sub-phase) had an effect on the total value recorded, when it should have no effect on the push-off itself or its consequences (the velocities and turn time). In this study, the different computed impulses did not seem to influence the turn time, confirming that the strategy adopted by elite swimmers is based on a reduction in contact time rather than a maximization of push-off force.

Non-significant observations may help to understand how velocity changed during the turn. The positive correlation between the speed at the force peak and the turn time gradually decreased with the push-off ending (Vmax, $r^{1 / 40.35}$; VG, $r^{1 / 40.23}$, Fig. 5) and became negative along the glide: the head-wall distances when the horizontal speed dropped to $2.2 \mathrm{~m} / \mathrm{s}$ (D22, $\left.r^{1 / 4}-0.25\right)$ and then to $1.9 \mathrm{~m} / \mathrm{s}\left(\mathrm{D} 19, r^{1 / 4}-0.38\right)$ were higher for the best turns. Due to a more streamlined position from the first contact (CUBei, Table 2), the decrease in speed during the glides following the best turns was less marked. However, these nonsignificant results may justify another study focused on the gain and loss of speed during the push-off and the subsequent gliding phase with the help of streamline indexes.

The total distance covered by the swimmer's head during the turn (TD) is a 3D parameter that reflected the moves along each axis: the round trip in the main direction of movement and also the depth and lateral deviations from an "ideally" short trajectory (Fig. 4). The statistical results indicated that the best turns were characterized by a reduced path length (Table 2). We note that the value of the Lasso estimated coefficient should be considered with caution. It may indicate that, by keeping the head-wall distance at the rotation (RD) and the speed at the force peak (VPe) constant, elite male swimmers should be able to reduce the total distance covered by $2.19 \mathrm{~m}$ to improve their turn time by $0.01 \mathrm{~s}$. This gain is not realistic because the maximum difference in TD for the studied group was about $1 \mathrm{~m}$. Nevertheless, this parameter still appears as a good indicator of the turn performance for expert swimmers because it points out excessive or unnecessary moves. By comparing three expert swimmers whose 3mRTT and TD are very different, we noted that a decrease in turn performance was associated with a close rotation and large lateral displacements (Fig. 4). From now on, coaches should monitor turn trajectories to reduce them and thus turn times. Future studies focused on this parameter are also warranted.

\section{Conclusion}

In male expert front crawl swimmers, the fastest turners are those who initiate their rotation further from the wall. This allows them to reach the wall in a slightly flexed position, thereby leading to a quick extension. These swimmers opt for a movement that is oriented forward and they focus on reducing the distance covered.

\section{Conflict of interest statement}

The authors confirm that there is no personal or institutional conflict of interest.

\section{References}

Abdel-Aziz, Y.I., Karara, H.M., 1971. Direct linear transformation from comparato coordinates into object space coordinates in close range photogrammetry. In Proceedings of the Symposium on Close Range Photogrammetry, American Society of Photogrammetry, Falls Church, VA, pp. 1-18.

Arellano, R., Brown, P., Cappaert, J., Nelson, R., 1994. Analysis of 50 m, 100 m, and $200 \mathrm{~m}$ freestyle swimmers at the 1992 Olympic games. Journal of Applied Biomechanics 10 (2), 189-199.

Blanksby, B., Gathercole, D., Marshall, R., 1996. Force plate and video analysis of the tumble turn by age-group swimmers. Journal of Swimming Research 11, $40-45$.

Challis, J.H., Kerwin, D.G., 1992. Accuracy assessment and control point config uration when using the DLT for photogrammetry. Journal of Biomechanics 25 (9), 1053-1058.

Chen, L., Armstrong, C.W., Raftopoulos, D.D., 1994. An investigation on the accuracy of three-dimensional space reconstruction using the direct linear transformation technique. Journal of Biomechanics 27 (4), 493-500.

Cossor, J.M., Blanksby, B.A., Elliott, B.C., 1999. The influence of plyometric training on the freestyle tumble turn. Journal of Science and Medicine in Sport 2 (2), 106-116.

Domenici, P., Batty, R.S., Similä, T., Ogam, E., 2000. Killer whales (orcinus orca) feeding on schooling herring (clupea harengus) using underwater tail-slaps: kinematic analyses of field observations. The Journal of Experimental Biology 203, 282-294.

Elipot, M., Hellard, P., Taïar, R., Boissiere, E., Rey, J., Lecat, S., Houel, N., 2009. Analysis of swimmers' velocity during the underwater gliding motion following grab start. Journal of Biomechanics 42 (9), 1367-1370.

Hay, J., 1988. The status of research on the biomechanics of swimming. In: Ungerechts, B.E., Wilke, K., Reischle, K. (Eds.), Swimming Science V, Proceedings of the $\mathrm{V}$ International Symposium on Biomechanics and Medicine in Swimming, International Series on Sport Sciences, vol. 18, Human Kinetics Books, Champaign, Illinois, pp. 3-14.

Lyttle, A., Blanksby, B., Elliott, B., Lloyd, D., 1999. Investigating kinetics in the freestyle flip turn push-off. Journal of Applied Biomechanics 15 (3), $242-252$.

Lyttle, A., Mason, B., 1997. A kinematic and kinetic analysis of the freestyle and butterfly turns. Journal of Swimming Research 12, 7-11.

Nakagawa, S., Cuthill, I., 2007. Effect size, confidence interval and statistical significance: a practical guide for biologists. Biological reviews of the Cambridge Philosophical Society 82 (4), 591-605.

Nicol, K., Kruger, F., 1979. Impulses exerted in performing several kinds of swimming turns. In: Terauds, J., Bedingfield, E.W. (Eds.), Swimming III, Proceedings of the III International Symposium on Biomechanics in Swim ming. International Series on Sport Sciences, vol. 8, University Park Press, Baltimore, pp. 222-232.

Pereira, S., Araujo, L., Freitas, E., Gatti, R., Silveira, G., Roesler, H., 2006. Biomechanical analysis of the turn in front crawl swimming. In: Vilas-Boas, J.P., Alves, F., Marques, A. (Eds.), Biomechanics and Medicine in Swimming X, vol. 6 (Suppl. 2), pp. 77-79 (Portuguese Journal of Sport Sciences).

Prins, J.H., Patz, A., 2006. The influence of tuck index, depth of foot-plant, and wall contact time on the velocity of push-off in the freestyle flip turn. In: Vilas Boas, J.P., Alves, F., Marques, A. (Eds.), Biomechanics and Medicine in Swim ming X, vol. 6 (Suppl. 2), pp. 82-85 (Portuguese Journal of Sport Sciences).

Psycharakis, S.G., Sanders, R., Mill, F., 2005. A calibration frame for 3D swimming analysis. In: Proceedings of the 23rd International Symposium on Biomechanics in Sports, Beijing, China

Puel, F., Morlier, J., Mesnard, M., Cid, M., Hellard, P., 2011. Three-dimensional kinematic and dynamic analysis of the crawl tumble turn performance: the expertise effect. Computer Methods in Biomechanics and Biomedical Engineering 14 (Suppl. 1), 215-216

Sanders, R.H., 2002. New analysis procedures for giving feedback to swimming coaches and swimmers. In: Gianikellis, K.E. (Ed.), Proceedings of the XX International Symposium on Biomechanics in Sports, Caceres, pp. 1-14.

Savitzky, A., Golay, M.J.E., 1964. Smoothing and differentiation of data by simplified least squares procedures. Analytical Chemistry 36 (8), 1627-1639.

Sibella, F., Frosio, I., Schena, F., Borghese, N.A., 2007. 3D analysis of the body center of mass in rock climbing. Human Movement Science 26, 841-852.

Silveira, G., 2007. Proposiea o de uma metodologia para coleta de dados da virada no nado crawl. CEFID, UDESC, Florianopolis, Brazil.

Thayer, A., Hay, J., 1984. Motivating start and turn improvement. Swimming Technique 20 (4), 17-20.

Tibshirani, R., 1996. Regression shrinkage and selection via the Lasso. Journal of the Royal Statistical Society-Series B (Methodological) 58 (1), 267-288.

Vilas-Boas, J.P., Fernandes, R., 2003. Swimming starts and turns: determinant factors of swimming performance. In: Sidney, M., Pelayo, P. (Eds.), Actes des 3'émes Journées Spécialisées de Natation. , Publibook, Paris, pp. 84-95.

Winter, D.A., 1990. Biomechanics and Motor Control of Human Movement, 2nd ed. Wiley-Interscience, New-York.

Wood, G.A., Marshall, R.N., 1986. The accuracy of DLT extrapolation in threedimensional film analysis. Journal of Biomechanics 19 (9), 781-785. 